\title{
INNOVATIVE METHODS FOR DEVELOPING PHYSICAL STRENGTHS AND ENDURANCE IN STUDENTS
}

\author{
M. Ivanova*, P. Petkov \\ Trakia University, Stara Zagora, Bulgaria
}

\begin{abstract}
Innovative methods for developing students' physical strength and endurance skills

A pedagogical experiment with 66 students (women) from first and second course from all specialties in the Faculties of Economics, Agriculture and Veterinary Medicine at Trakia University, Stara Zagora, randomly divided into an experimental group (36 students) and a control group (30 students), was carried out. The aim of the study was to establish the impact of innovative methods for developing students' physical strength and endurance skills. Theoretical analysis, pedagogical experiment, spatio-pedagogical testing, pedagogical observation, variation analysis, graphical analysis and comparative analysis were applied to solve the research goal. A test battery comprising of 20 morpho-functional indicators and 13 indicators for physical strength and endurance was developed. The results and analysis showed that the experiment was successful and the developed fitness program with expanders was effective. The data obtained is indicative that the inclusion of the developed fitness program with expanders in the curriculum of Physical Education and Sports in the university will lead to an improvement in the physical skills strength and endurance, of the students.
\end{abstract}

Key words: university, expanders, experiment

\section{INTRODUCTION}

Student years of humans are associated with increased stress, increased mental workload and reduced physical activity. With the help of physical inquiry and feedback, it is easier to resolve and resolve to be made quicker and more efficient. The influence of the sport on the the human organism has a major effect, in order to implement the didactic principles and metadistributions. Exactly that is the reason for the improvement of the organization and the contents of the university physical inquiry and newsletter at our site was up-to-date (1-3).

In recent years, in order to stimulate sportphysical activity and improve the physical training of students, it has been increasingly drawn by sports professionals to update the content of familiar sports disciplines and to introduce new ones (4).

In order to be effective in the field of fitness of students, it is necessary to be able to plan and

\footnotetext{
*Correspondence to: Mariya Ivanova, Trakia

University, Stara Zagora, Bulgaria, e-mail: mimi0101@abv.bg, GSM 0887527829
}

define the goals and objectives that are required to be implemented in the educational process. The teaching of gymnasium in higher schools should be aimed at strengthening health, speeding up mental retrieval, maintaining a mental health situation, support of the care, confidence, assurance of the students $(5,6)$.

The aim of the launch is to establish innovative methods for developing physical abilities and endurance in students.

To achieve the goal the following tasks were set: 1. Study of literary sources.

2. Develop a test battery.

3. Develop and experiment a dedicated fitness model.

4. Process and analyze test data.

The following methods were used to solve the research goal:

1. Theoretical analysis,

2. Spatio-pedagogical testing,

3. Pedagogical experiment,

4. Pedagogical observation,

5. Variation analysis,

6. Graphical analysis,

7. Comparative analysis 
A pedagogical experiment was carried out with 66 students from the first and second courses of all the Faculty of Economics, Faculty of Agriculture and Faculty of Veterinary Medicine at the Thracian University of Stara Zagora during the winter semester of the academic year 2018/2019. The students were divided into the principle of the experimental group (36 students) and the control group (30 students). The average age of the students is 19.34 years. The average height is $163.09 \mathrm{~cm}$.

The test battery includes the following tests:

1. Motion abilities

2. Length jump from place

3. Hovering to cancel

4. Tilting a Medical Ball with Two Hands Above the Head - Forward

5. Tilting a Medical Ball with Two Hands Above the Head - Back

6. Plank

7. Holding dumbbells to the side

8. Shuttle $10 \times 10$ meters

\section{ANALYSIS OF RESULTS}

The developed fitness model consists of exercises with expanders for the different muscles, with a certain sequence and dosage (30 seconds of exercise - 30 seconds of rest). The classes took place in Physical Education and Sports classes twice a week for 13 weeks during the winter semester of the academic year 2018/2019.

After the "Length jump from place" test, the students showed the following results - the average values for the first study of $\mathrm{EE}$ were $150.33 \mathrm{~cm}$ and for the second one $156.58 \mathrm{~cm}$. Positive growth of $6.25 \mathrm{~cm}$. Students from KG showed average values of $153.86 \mathrm{~cm}$ of the first study and $152.66 \mathrm{~cm}$ of the second one - a decrease of the results by $1.2 \mathrm{~cm}$. The difference in the growth of the average values of the two groups is $7.45 \mathrm{~cm}$ in favor of EW. The graphical results are shown in Figure 1.

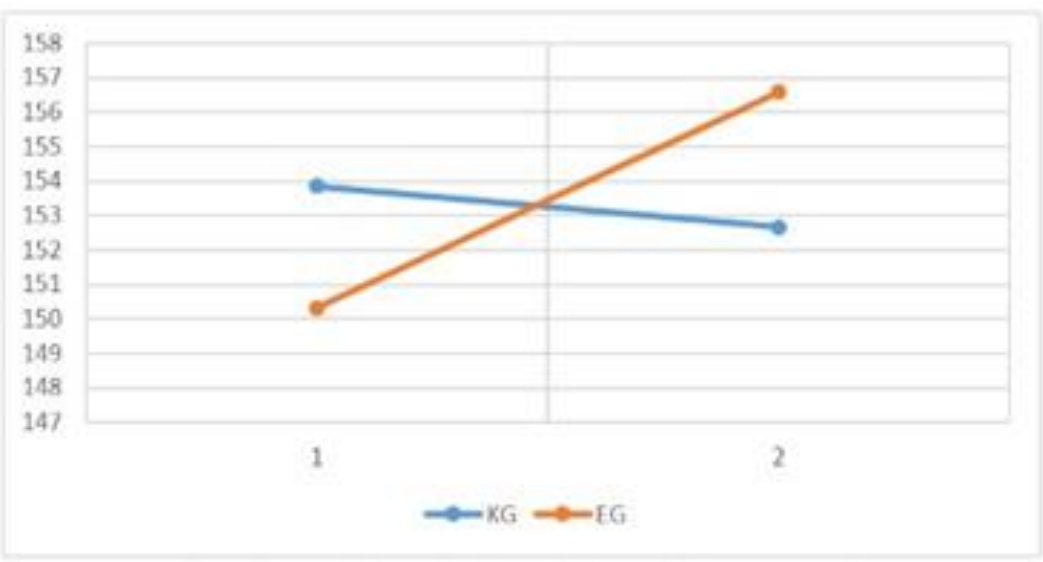

Figure 1. Test Results "Length jump from place"

In the "Hovering to failure" test, the results of the EA from the first study test showed 35.88 seconds. and 38.02 seconds. the second, a positive gain of 2.32 seconds. KG showed average values of $34.96 \mathrm{sec}$. the first and 32.3 seconds. of the second study. For KG a decrease of the mean values in the outgoing tests was observed with $-2,6 \mathrm{sec}$. The difference in the growth of the mean values of the two groups is $4.98 \mathrm{sec}$ in favor of EG. Graphically, the results are shown in Figure 2.

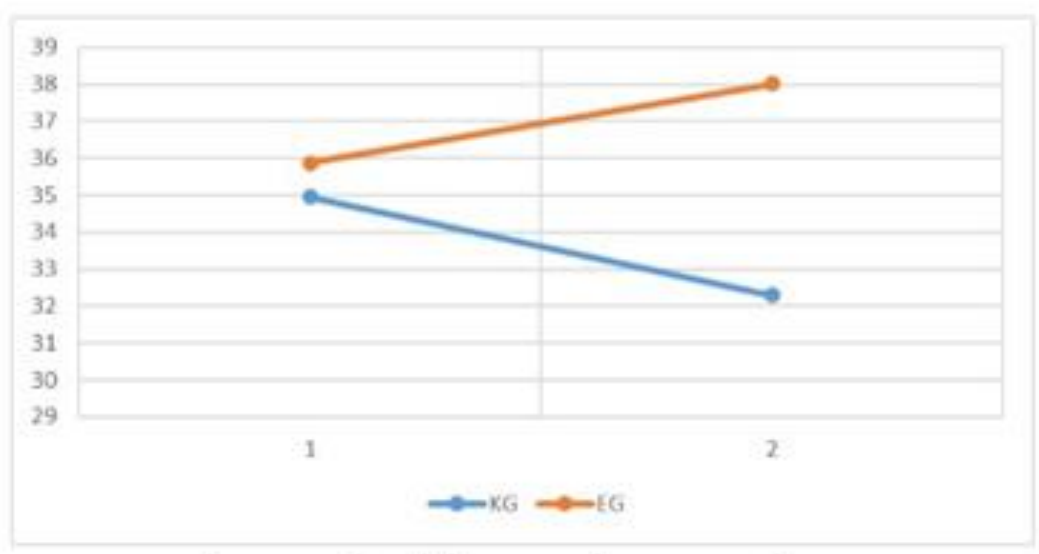

Figure 2. Results of the "Hovering to cancel" test 
On the Planck test, the students of the EA showed average values of 83.66 seconds. of the first study. After application of the experimental fitness program, they showed average values of the outgoing test of $92.75 \mathrm{sec}$. We report an increase of 9.09 seconds. KG showed average values of the intake tests of $82.3 \mathrm{sec}$. and 79.6 sec. on outbound testing. There is a decrease in average values of -2.7 seconds at the KG. The difference between the mean values of the growth of the two groups is 11.79 seconds. The graphical results are shown in Figure 3.

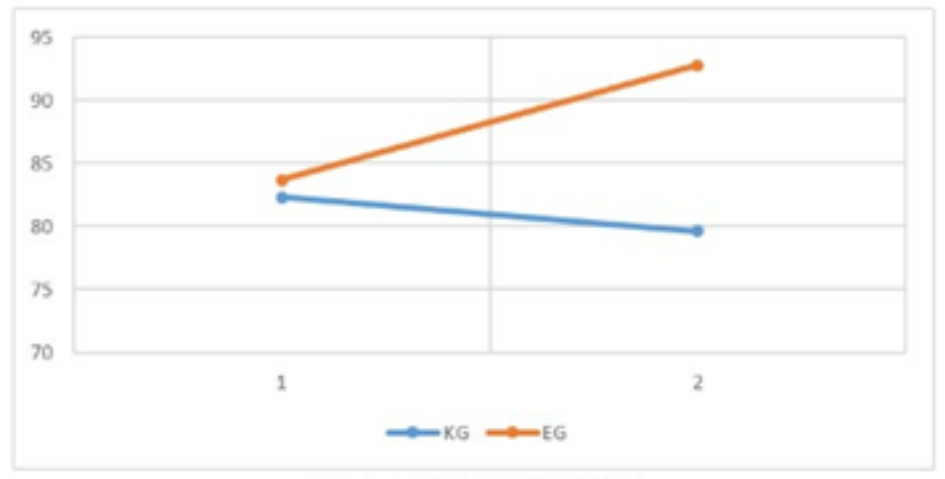

Figure 3. Planck test results

On the "Holding of dumbbells to derailment" test, EA showed average values of 48.97 seconds. of the first study and $55.55 \mathrm{sec}$. the second one. A positive gain of 6.58 seconds. The mean $\mathrm{KG}$ values of the first study were 50.3 seconds. and $48.1 \mathrm{sec}$. of the second study. $\mathrm{KG}$ showed a decrease in results by $-2.2 \mathrm{sec}$. The difference in the growth of the two groups is 8.78 seconds in favor of EG.

The graphical results are shown in Figure 4.

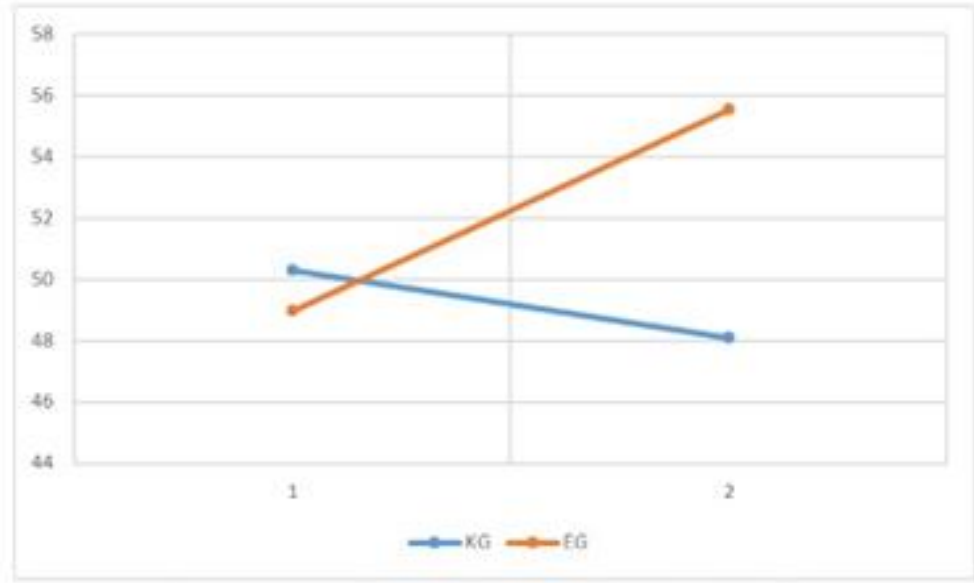

Figure 4. Test results "Holding dumbbells to the side"

On the "Tilting a Medical Ball with Two Hands Over the Head - Forward" test of the first TG test showed average values of $419.44 \mathrm{~cm}$ and the second $443.33 \mathrm{~cm}$. Positive growth of $23,99 \mathrm{~cm}$ after applying the experimental fitness program. The KG results are $474.33 \mathrm{~cm}$. of the first test and $478.5 \mathrm{~cm}$. the second one. The growth of the $\mathrm{KG}$ is $4,17 \mathrm{~cm}$. The difference in the growth of the mean values between the two groups is 19.72 $\mathrm{cm}$ in favor of the EW. The graphical results are shown in Figure 5.

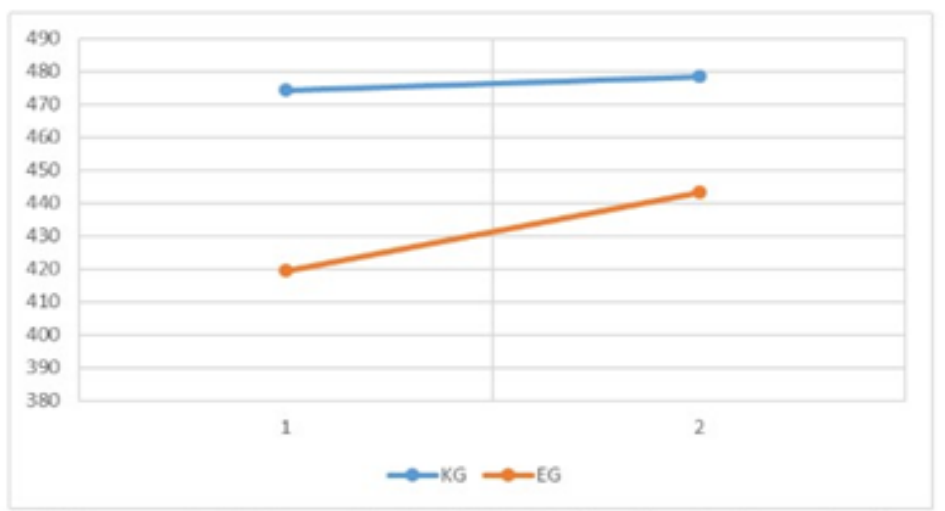

Figure 5. Test results "Tilting a Medical Ball with Two Hands Above the Head - Forward " 
On the "Tilting a Medical Ball with Two Hands Above the Head - Back" test of the first TG test showed average values of $464.16 \mathrm{~cm}$ and the second $501.66 \mathrm{~cm}$. A positive growth of $37.5 \mathrm{~cm}$ after applying the experimental fitness program. The KG results are 522.66
IVANOVA M., et al. $\mathrm{cm}$. of the first test and $515.2 \mathrm{~cm}$. the second one. There was a decrease in mean $\mathrm{KG}$ values of $-7.46 \mathrm{~cm}$. The difference in the growth of the mean values between the two groups is $30.04 \mathrm{~cm}$ in favor of EG.

The graphical results are shown in Figure 6.

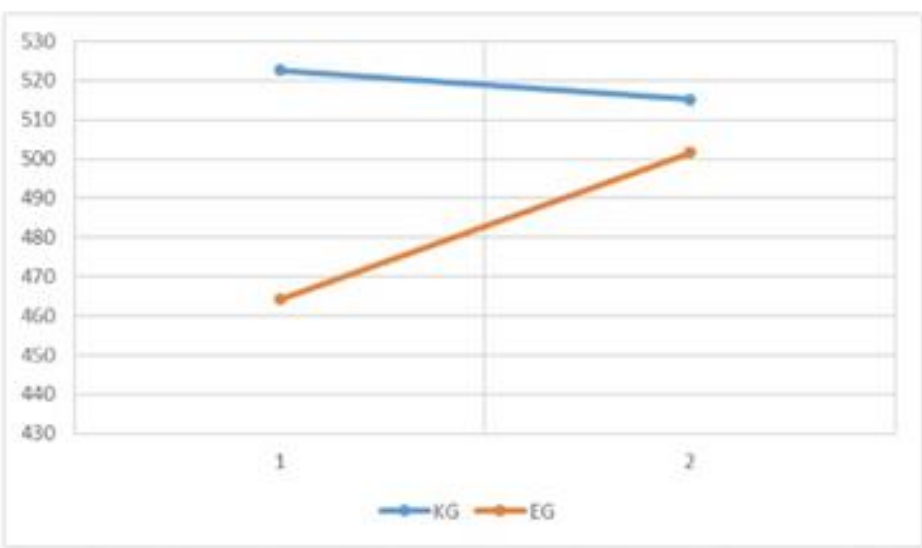

Figure 6. Test results "Tilting a Medical Ball with Two Hands Above the Head - Back"

On the "10k10meter shuttle" test, the students at the first test showed average results of 32.61 seconds. and 31.69 seconds. of the second test. Positive growth after the experimental fitness program is 0.92 seconds. At KG mean values of the first test are 32.42 seconds. and $33.8 \mathrm{sec}$. of the second test. KG showed a decrease in results by -1.38 seconds. The difference in the mean values of the test gain between the two groups is 2.2 seconds in favor of EG. Graphically, the results are shown in Figure 7.

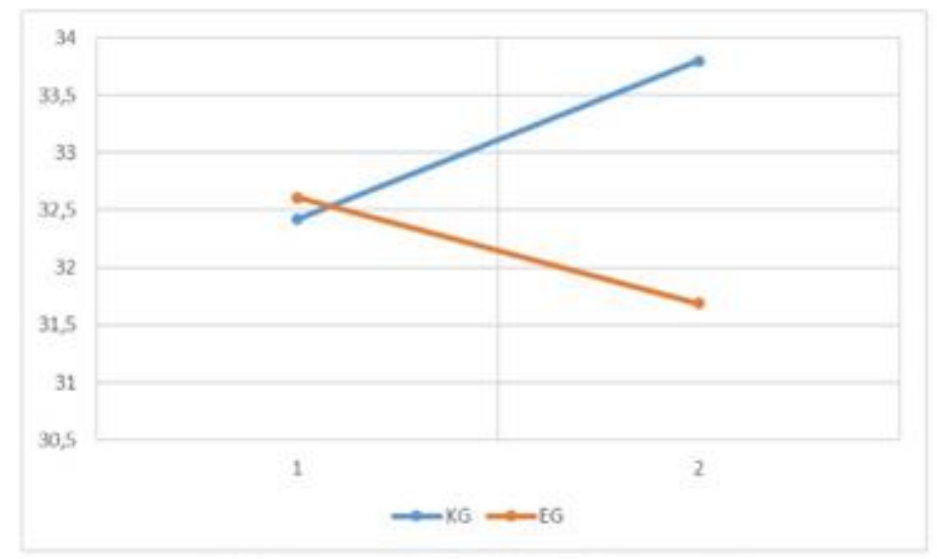

Figure 7. Test results "Shuttle 10x10 meters"

The following conclusions can be drawn from the scientific research:

1. Developed author's fitness program with expanders has improved the physical qualities we see.

\section{RECOMMENDATIONS}

1. Inclusion of the developed fitness program with expanders in the physical education and sports curriculum in the higher school will lead to an improvement in the physical strength and endurance of students.

\section{REFERENCES}

1. Dyakova, G., P. Peeva, A. Bozhkova, Influence of the PG FITNES program on the physical fitness of female students. 12- th European Congress of Sport Psychology, Sport and Exercise Psychology Bridges Between Disciplines and Cultures, Halkidiki, Greece, Book of Long Papers, ISBN: 978-960-89923-0-6, №021, p. 310312, 2007.

2. Dyakova, G., Effect of Body-programme on physical qualities and morpho-functional indices of female students. Sport \& Science, ISNN 1310-3393, Extra issue, Proceeding book, XVI ISC "Olympic Sport and Sport for all" \& VI ISC "Sport, Stress, Adaptation", p. 252-256, 2012.

3. Peeva, P., Dyakova, G., Effect of the training program Cardiocallanetics on some morphofunctional characteristics of female 
IVANOVA M., et al.

students. 4-th International Scienfic Congress Sport, Stress, Adaptation, ISBN 978-954-723-006-4, p. 614-617, 2006.

4. Dyakova, G., Peeva, P., Nikolova, E., Bodifit training program - methodology and efficiency. Sp. Sports and Science, ISSN 1310-3303, S., nos. 3, p. 29-36, 1997.
5. Dyakova, G., Peeva, P., Exploring the effectiveness of Quick mini-step callanetics (Galiletics). Rousse University "Angel Kanchev" Scientific Papers, ISSN 13113321, Volume 45, Series 5.4, p.71-75, 2006.

6. Jelqzkov, Basics of Sports Training, Sofia, 1998. 